collected with a 5-ml. water sample in the same area.

Mr. J. Corlett (Britain) described the zooplankton collected at weather stations $I$ and $J$ and showed that the total quantities were greater in 1958 than in 1957. Mr. Hansen noticed that Evadne nordmanni had also been found in the Norwegian Sea. Dr. Fraser said that Thalia democratica found by the Plankton Expedition in 1888 off west Scottish coasts appeared for the first time off west Scottish coasts in 1958.

Dr. W. Höhnck (Federal Republic of Germany) presented an interesting paper on the quantity and types of fungi in the sea and on the sea bed. The majority of samples taken showed devolopment of hyphæ.

Fisheries. Dr. Eggvin presented a paper by $\mathrm{Mr}$. L. Midttun on echo-surveys in the Barents Sea. In general, there was a relationship between the dis tribution of echo-traces and isotherms in the Barents Sea.

Conclusions. There appeared to be two main conclusions from the biological papers:

(1) The International Geophysical Year differed in two respects from somo other years, in indicator species and in quantity of living material.

(2) Three advances in productivity studies were revealed: $(a)$ the use of transparency as an index of productivity under certain limited conditions; (b) the fairly close relationship between standing stock (as chlorophyll) and productivity (as carbon-14 count); (c) the use of very small samples of phytoplankton $(0.3 \mathrm{ml}$.$) and zooplankton (5 \mathrm{ml}$.) to give sensible estimates of carbon in living material.

A. J. LEE

D. H. Cushing

\title{
EFFECTS OF FOREST AREAS ON WATER RESOURCES, AND THE TECHNIQUE OF LYSIMETRY
}

$\mathrm{B}$ ETWEEN September 8 and 13, two symposia were held in Germany by the International Association of Scientific Hydrology, at HannoverschMünden, where the Forestry School of the University of Göttingen is established.

One symposium concerned the influence of wooded areas on the elements of the water balance. Thirty. five papers were presented, ten from the U.S.S.R., eight from the United States, four from Great Britain, two each from Finland and Poland and one each from the Belgian Congo, Czechoslovakia, Denmark, French Africa, Germany, Holland, Hungary, South Africa and Switzerland.

The other symposium dealt with the technique of lysimetry and the causes of error in results obtained. There were seventeen papers, four from the United States, three from Holland, two each from the Belgian Congo, Germany and the U.S.S.R., and one each from Austria, France, Hungary and Great Britain.

The papers were made available in printed form at the meeting and have since been placed on sale by the Association*. Most of them are written in English, and the few others in French or German.

The symposia were attended by more than a hundred hydrologists, from other countries as well as from those which contributed papers. There was naturally a strong Gorman representation, while both the United States and Great Britain had important teams. It was regretted that, while the U.S.S.R. had sent several valuable papers, their authors were not present to introduce them.

Below is given an appreciation of each of the two symposia and of a two-day visit paid afterwards to German field-stations concerned with one or other of the two subjects that had been discussed.

It is expected that the discussions of the papers will be reported briefly in the quarterly issues of the Association's Bulletin, the price of which is 150 Belgian francs yearly.

* Publication No. 48 (Vol. 1 : Water and Woodlands). Pp. 340. 300 Belgian francs. Publication No. 49 (Vol 2: Losimeters). Pp. 340. 150 Belgian francs. Obtainable from Mr. Arthur $\mathrm{F}$. Bird, 66 Chandos Place, London, W.C.2, or the Secretary of the International Association of Selentific Hydrology, Prof. L. J. Tison, 61 Rue des Ronces, Gentbrugge, Bolgium.

\section{Water and Woodlands}

In many countries, increasing concern with the provision and maintenance of adequate water supplies in the face of continuously increasing demands has stimulated considerable interest in the scientific management of this most vital of our natural resources. With fuller appreciation of the importance of form of land use in catchment areas, much attention has naturally been directed to the role of a forest cover. Compared with other countries such as the United States and Germany, Britain is a rather late entrant into this field, but within recent years, the problem has come very much to the fore and there can be no doubt, especially in view of the recent drought, that we shall have to devote very much more attention to this important issue. As elsewhere, differences of opinion exist as to whether, from the hydrological point of view, our catchments are better under forest than, say, under pasture. The answer is by no means as clear-cut as some would make out; the hydrological relationships involved are most complicated and objective quantitative assessments beset with considerable practical diffieulties. It was therefore most timely that under the auspices of the International Association of Scientific Hydrology much of the experience and present knowledge in this field could be surveyed and discussed.

Almost half the contributions were concerned with investigations on the catchment scale. In principle, these involve the measurement of precipitation and run-off (both surface and subsoil), normally by stream gauging; despite the substantial cost of installation and maintenance, and, very often, difficulties in ensuring absence of leaks and a reasonable standard of precision, this approach is still essential for the provision of the basic hydrological data appropriate to the problem as a whole. As an alternative to the 'straightforward' comparison, say, between forested and non-forested catchments, Idson (U.S.S.R.) preferred continuous measurements on an area under the influence of a varying forest cover. Because of the well-known difficulties in ensuring comparability between catchments, this 
latter approach would generally seem to be the more reliable one; the regression techniques used by Idson and by Anderson and Hobba (U.S.A.), in which run-off is related to the various meteorological, soil or land-use factors which influence run-off, offer an approach which allows for a more complete interpretation of the complex relationships involved.

In those countries where snow forms an important source of water there was general agreement as to the beneficial influence of a forest cover; the data of Anderson and Hobba (U.S.A.), Goodell (U.S.A.), Martinelli (U.S.A.) and Sozykin (U.S.S.R.) clearly showed that through accumulation and the shelter provided, the forest retards thawing, reduces the danger of spring floods and prolongs the supply of melt water. The difficulties of measuring snowfall and the need for further investigation were made clear in the papers of Martinelli (U.S.A.) and Sepännen (Finland).

General recognition was also given to the higher permeability and greater storage capacities of soils developed under forest, leading to reduced surface run-off, less erosion and a more prolonged yield of water during drought. Anderson and Hobba (U.S.A.), Valek (Czechoslovakia) and Banky (Hungary), among others, clearly demonstrated the regulatory effect of the forest on stream flow; Rodier (French West Africa) showed that flood peaks were 8-12 times lower from forest than from savannah, and the importance of this effect was recognized by Wicht in his published recommendations for the management of catchment areas in South Africa.

So far as absolute quantities were concerned, most contributors were prepared to accept a somewhat lower yield from a forested area as compared with areas under other vegetative covers. Meginnis (U.S.A.) provided one of the more extreme examples from the classical Coweeta experiments in North Carolina, where clear cutting of mountain hardwood forest increased the annual yield by 11-17 in. and cutting of the shrubby understory by 2 in. To conserve water in the south-western United States, Horton recommended the clearance of phreatophytes (vegetation with permanent access to ground water) along streams and rivers. While such losses from forest stands were generally attributed to higher levels of transpiration, usually because of deeper rooting and access to water during dry periods, some would attempt to explain at least some of the losses to interception of precipitation by the foliage. Thus, Eidmann (Germany) stated that because it intercepts appreciably less rainfall, a beech forest conserves more water than a spruce forest. The implied assumption that intercepted water means a corresponding loss to the soil was contested by Leyton and Carlisle (Great Britain), who produced experimental evidence indicating, as might be expected, a marked fall in transpiration following wetting of the foliage ; attention was also directed to the possibility of rather large errors in the estimation of through-fall in a stand using a limited number of gauges, and the increase in accuracy obtainable when these were replaced by troughs with larger collecting areas. The papers of Bochkov and certain other Russian contributors provided an interesting contrast to the generally prevailing opinion that a forest cover means a lower yield of water. These authors argued that, because of deep ground-water movement in forest soils, the gauging of small streams draining small catchments may under-estimate the yield and that over large areas, in certain cases at least, yield from the forest may be even higher than that from open land. Sokolovsky (U.S.S.R.) also claimed that an increased water loss from forest by transpiration may be balanced by reduced evaporation from the soil. It is possible, therefore, that even in the case of water yield, final judgment on the effect of a forest cover may have to be postponed; from the point of view of energy relations, at least, one would not expect large differences in the loss of water from different types of vegetative cover.

A number of contributors described other means of investigating quantitatively the hydrological relations of a site. Visser (Holland) explained his soil moisture flow approach, which provides an estimate of the water balance from measurements of rainfall, potential evaporation and the ground-water level in the soil and in ditches; Lebedev (U.S.S.R.) also provided an interesting analysis of ground-water dynamics under forest and grass covers. From measurements of water loss from detached shoots of Scots pine, Rutter (Great Britain) gave evidence of transpiration values apparently exceeding Penman's estimate of $E_{T}$ (potential evaporation from grass); this, combined with his observations that the trees continued transpiring even down to a soil moisture deficit of 7 in. or more, introduces still further problems in our interpretation of forest hydrological relationships. As yet another approach to the estimation of water losses from forest stands, Leyton (Great Britain) discussed the possibility of measuring the volume rate of sap flow in tree stems by the heatpulse method originally introduced by Huber. It was regretted that, apart from a few words in discussion by Baumgartner (Germany), there was no opportunity to learn of the present status regarding the energy-balance approach.

In summarizing one's general reaction to the papers reported above and to the subsequent dis. cussions, one cannot but be impressed by the magnitude of the efforts made to gain a better understanding of the hydrological relationships of the forest. At the same time it is evident that much still remains to be done. So many aspects have to be considered and so many factors are involved that it is usually not possible to extrapolate findings from one area to another ; in this respect the use of regression analysis to define certain underlying relationships has a very promising future. It is also clear that most countries do not look at the forest simply as a potential drain on water supplies, to be avoided wherever possible. As H. C. Storey, director of the U.S. Forest Service Division of Watershed Management Research, pointed out, the emphasis must be on the multiple use of the forest; Lambor (Poland) echoed the same theme in his recommendations for a water economy plan based on the proper appreciation of the comprehensive role of a forest cover.

Following the symposium, an excursion was made to various forest catchment experiments in the area. Eidmann (Düsseldorf) demonstrated two of his seven stream-gauge installations set up in small eatchments to investigate the influence of various types of forest cover and of forest practice, primarily on water yield; at Lahnhof, beech and spruce forest are being compared and at Helgersdorf, coppice and high forest. The Ruhrtalsperrenverein, the organization largely responsible for supplying water to the Ruhr industries, has nine similar installations, two of which, on the Runkhauserbach (99 per cent forest) and the Königswasser (97 per cent arable), were also inspected. 
Coming from a country with similar water problems, but without a single catchment experiment designed specifically to investigate forest influences, one is greatly impressed by the enthusiasm with which these problems are being tackled in Germany. It is not difficult to criticize many of these installations; precipitation measurements, stream-gauge design, the possibility of leaks and questionable comparability of catchments, all raise problems which could readily intimidate the ultra-cautious, particularly in view of the costs involved. Nevertheless, with the example set by the Americans, Germans and other nationals, and with access to their knowledge and experience, can wo in Britain afford not to set up similar experiments of our own?

L. LEYTON

\section{Lysimeters}

A lysimeter is an apparatus used for measuring the quantity or quality of water which has percolated through a container which is filled with soil or similar material. It is easy to see that, within such a definition, lysimeters can be used for such a variety of specific purposes that each installation must be considered on its own merits ; an ever-present danger is to interpret what is measured by means of the lysimeter as being representative of any conditions other than those obtaining in the lysimeter itself.

Lysimeters are commonly installed to throw light on what happens in the field, where many different factors affect the amount of percolated water. The position is essentially similar to that encountered in measuring temperature, rainfall and other meteorological factors, where, however, arbitrary standards of measurement have been accepted for purposes of making comparisons between values obtained at different sites. So far, standard conditions have not been accepted for lysimeter installations and readings, and indeed comparatively few suggestions have been put forward for standardization of observations.

It is thus not surprising that several of the papers read at the symposium described lysimeters which could throw some light on what happened, with the passage of time, only in particular circumstances. Various ingenious and, in some cases, expensive installations have been set up, in which care has been taken to avoid such things as disturbance of the natural soil profile, or of the homogeneity of the vegetation cover. But in almost none were there lacking unmeasured variables which, even though in some cases a correlation with adjoining field conditions could satisfactorily be established, allowed of any trustworthy comparison between one site and another.

W. C. Visser, of the Netherlands, was one of those who read papers pointing out that conditions in a lysimeter are essentially artificial, and that the factors introduced by this artificiality need to be measured or eliminated. Visser particularly recommended water-flow potential measurements in the field to 'ealibrate' the lysimeter measurements ; this involves measuring ground-water depth, tension in the capillary zone, tensions in the plants, and vapour pressures in the air. K. Ubell, of Hungary, placed emphasis on the need to have constant records of the temperature gradients in the field and in the lysimeter. Harrold and Dreibelbis, in describing some of the work at the well-known installations at Coshocton, Ohio, showed themselves vividly aware of difficulties, which have failed to be understood by some who have quoted the Coshocton results too uncritically.
Lysimeters can broadly be divided into those measuring volume and those measuring weight. There is much to be said for the latter, because not only do they help to overeome the problem of ehanges in the amount of water stored in the lysimeter, but they also enable changes to be recorded as continuously as is desired; lysimeters working on volumes of outflow water necessarily have by contrast a much more considerable time-lag. Several speakers, however, pointed out that weighing lysimeters were not the complete answer which some had incautiously considered them to be; for example, one is not sure whether what is being woighed at one season is strictly comparable to that being weighed at another time of the year.

E. J. Winter (Great Britain) read a joint paper by P. J. Salter, G. Stanhill and himself describing the installations at the National Vegetable Research Station in Warwickshire. Besides directing attention to some interesting and significant results which need further investigation, he stressed that much satisfactory and adequate practical advice can now be given to growers, even though more research is needed to elucidate the mechanisms of, and variations in, the water balance.

G. F. Makkink, in describing the various installations in the Netherlands, made the following useful summary remark: "It is considered the final aim of lysimeter research to gain an insight into the water balance of any natural soil-profile as a function of climate, vegetation and movement of the ground water. This aim widely surpasses the limited scope of the lysimeter observation of the separate institutions who own them". The recognition of this has led to appreciable progress in the Netherlands in co-ordinating results.

Several speakers, particularly G. L. Dupriez (Belgian Congo) and F. H. W. Green (Great Britain), emphasized the value of first obtaining observations of potential evapo-transpiration, under 'standard' conditions, at a network of stations. Cheap oil-drum lysimeters were found to be quite adequate for this purpose, if both sited and handled under comparable conditions. Green pointed out that, by simple subtraction, one could get reasonably reliable values of the seasonal differences in 'water deficit' and 'water surplus' from station to station, even where the absolute values of potential evapo-transpiration and of rainfall were open to doubt. In this connexion, several speakers emphasized the difference betwoen the rainfall measured in rain-gauges at the standard height and that falling on the ground. In both Britain and Germany this seemed to be of the order of rather more than 5 per cent ; ground-level gauges are therefore installed at most German lysimeter stations.

One of two week-end excursions at the end of the symposium was devoted primarily to visiting lysimeter installations. The first of these visited was in the Senne heathlands, near Bielefeld, and was operated in connexion with the water undertaking of that town. It consisted of four weighing lysimeters, one metre square cross-section, filled (in three cases) with 'monolith' blocks from three different soil profiles found in the area (the fourth was a 'disturbed' block from one of the areas). None of these lysimeters was irrigated, so that, particularly in a dry year like 1959, the lysimeters could supply facts but not explanations.

The second place visited was to an ingenious forest installation at Bossendorf, near Haltern, in Westphalia. Here, in addition to a more orthodox 